\title{
Fish Community Structure in the Pyeongchanggang River
}

\author{
Jun Kil Choi* \\ Department of Biological Science, Sangji University, Wonju 220-702, Korea
}

\begin{abstract}
Fish community structure in the Pyeongchanggang River was investigated from April to November 2009. About 900 individuals representing 24 species from eight families at six sites in the Pyeongchanggang River were collected. It was similar to the 2001's survey and it was less than 2006's survey. The Korean endemic species, Zacco koreanus was the most abundant, whereas subdominant species were native species, such as Pungtungia herzi, Zacco platypus, Rhynchocypris kumgangensis and Rhynchocypris oxycephalus. Three endangered species were collected at the sampling area, Acheilognathus signifier (relative abundance [RA] 0.9\%), Pseudopungtungia tenuicorpa (RA 1.4\%), and Cottus koreanus (RA 3.6\%). One natural monument species, Hemibarbus mylodon, was included. According to the analysis of ecological indicator characteristics, the relative proportion of tolerant species was $6.3 \%$ (57 individuals), whereas the proportion of sensitive species was $65.9 \%$ (593 individuals). Species evenness, richness and diversity indices decreased gradually through the month from April to November during the study. Community indices in Pyeongchanggang River showed a high evenness index $\left(\mathrm{J}^{\prime}>0.6\right)$, a low level of species richness $(\mathrm{R}<3.5)$ and a medium level of diversity $\left(1.5<\mathrm{H}^{\prime}<3.5\right)$. An ecological river health assessment based on the index of biological integrity (IBI), indicated that ecological river health varied depending on location and time of sampling. However, the average IBI score was $25(n=24)$, indicating a "fair condition" in the Pyeongchanggang River.
\end{abstract}

Keywords: Ichthyofauna, community structure, IBI

\section{INTRODUCTION}

Streams and rivers play an important role in our lives. They have great economic, social, cultural and environmental value and perform a number of ecological functions such as modulating streamflow, storing water, removing harmful materials from water, and providing habitat for aquatic and terrestrial plants and animals (Federal Interagency Stream Restoration Working Group, 1998).

Monitoring the status and trends in freshwater biota and ecosystems is essential to quantify human impacts and evaluate the effectiveness of management actions (Allan and Castillo, 2007). The significance of monitoring fish assemblages is primarily to comprehend the characteristics of fish fauna, the understanding of which is necessary for effective conservation and management of fisheries resources (Friedlander and Parrish, 1998).

The Pyeongchanggang River which originates in Nodong-ri, Yongpyeon-myeon, Pyeongchang-gun, Gangwondo join with the Donggang River in Hasong-ri, Yeongwoleup, Yeongwol-gun, Gangwon-do and it is a total of $149 \mathrm{~km}$ extension. Year of river flow is abundant and the river is relatively well-maintained in the appearance of natural rivers.

Several studies on fish communities have been conducted on the Pyeongchanggang River. The distribution of fish species in Gangwon-do was investigated by Choi (1986), followed by an evaluation of biological habitat assessment by An et al. (2001). The most recent study concerned fish community and inhabitation of legally protected species by Lee et al. (2006).

The aim of this study was to investigate fish community structure and river health in the Pyeongchanggang River, South Korea, using the index of biological integrity (IBI).

\section{MATERIALS AND METHODS}

\section{Study area}

Four sampling programs were conducted at six stations in the Pyeongchanggang River, located in Pyeongchang District, Gangwon-do, South Korea. The following stations were investigated for this study (Fig. 1). (c) This is an Open Access article distributed under the terms of the Creative Commons Attribution Non-Commercial License (http://creativecommons.org/ licenses/by-nc/3.0/) which permits unrestricted non-commercial use, distribution, and reproduction in any medium, provided the original work is properly cited.
*To whom correspondence should be addressed

Tel: 82-33-730-0434, Fax: 82-33-730-0430

E-mail: jkilchoi@sangji.ac.kr 
1. Nodong-ri, Youngpyeon-myeon, Pyeongchang-gun, Gangwon-do (Nodong-bridge).

2. Heujeong-ri, Bongpyeong-myeon, Pyeongchang-gun, Gangwon-do (Heungjeong-gegok).

3. Gaesu-ri, Daehwa-myeon, Pyeongchang-gun, Gangwondo (Gaesu-bridge).

4. Bangrim-ri, Bangrim-myeon, Pyeongchang-gun, Gangwon-do (Gupo-bridge).

5. Maji-ri, Pyeongchang-eup, Pyeongchang-gun, Gangwondo (Dodon-bridge).

6. Ongjeong-ri, Sa-myeon, Pyeongchang-gun, Gangwondo (Gwangjeon-bridge).

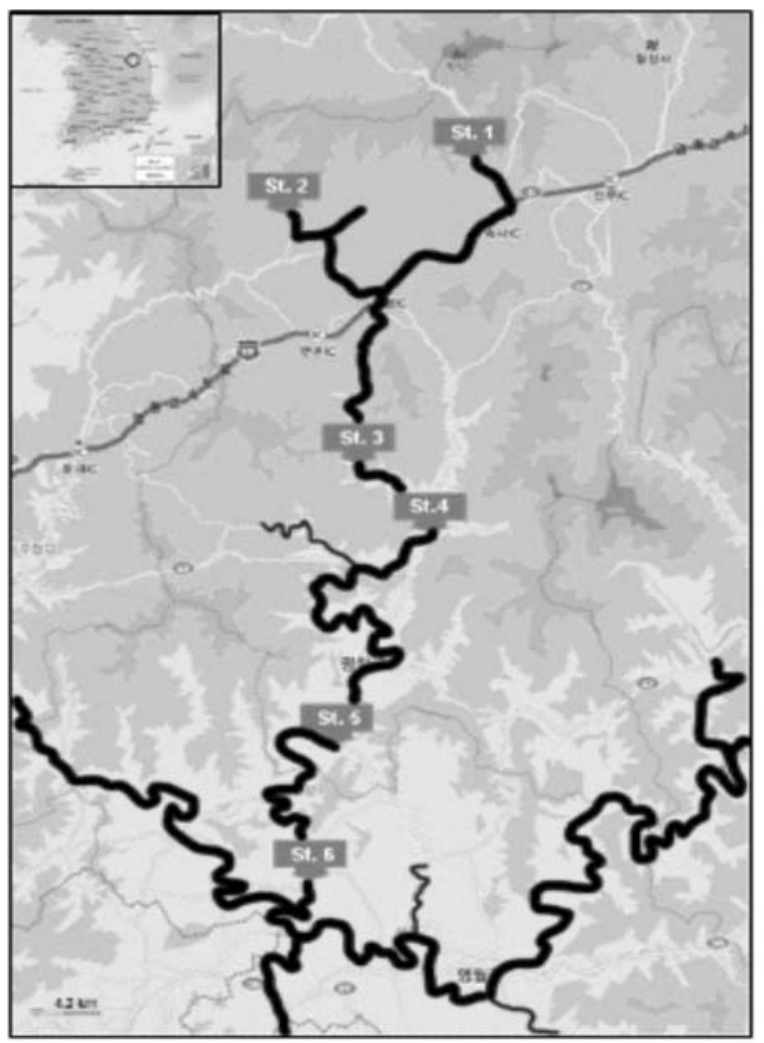

Fig. 1. Map of the Pyeongchanggang River sampling sites.

\section{Sampling methods and data analysis}

Fish were sampled from April-November 2009 (Apr 24-25; Aug 14-15; Oct 7-8; Nov 11-12). Fish sampling was conducted at the site using cast nets (mesh size, $7 \times 7 \mathrm{~mm}$ ) and hand nets (mesh size, $4 \times 4 \mathrm{~mm}$ ), according to the catch per unit effort method (Ohio Environmental Protection Agency, 1989). Collected species were fixed in $10 \%$ formalin, identified and classified in the laboratory using the methods described by Kim and Park (2002) and Kim et al. (2005). Sensitive and tolerant species were classified with reference to previous studies. All fishes were examined for external deformities, erosion (skin, barbells), lesions (open sores, ulcerations) and tumors (DELT anomalies), based on the criteria of Sanders et al. (1999).

A dominance index was calculated using the Simpson's dominance index (Simpson, 1949). Species diversity $\left(\mathrm{H}^{\prime}\right)$ was calculated by Shannon and Weaver (1949) which is more sensitive to the presence of rare species, and, thus, to species richness. The evenness index $\left(\mathrm{J}^{\prime}\right)$ was calculated using Pielou's evenness index (Pielou, 1966), and the species richness index (R) was calculated using Margalef's species richness (Margalef, 1958).

\section{Metric systems for the IBI}

The eight-metric system was adopted for the IBI in Pyeongchang Stream, rather than the 12-metric system suggested by Karr (1981) due to the cost-effective strategy and difficulties evaluating the metrics of long-lived fish and water-column species.

As shown in Table 1, ratings of 5, 3 and 1 were assigned to each metric. The three ratings were evaluated by the maximum species richness line, which was developed by Rankin and Yoder (1999), Hugueny et al. (1996) and Karr (1981). The sum of those ratings (5, 3, and 1) provided an IBI value at each station of the Pyeongchanggang River.

Thus, we evaluated the sampling stations as four integrity classes of excellent (36-40), good (26-35), fair (16-25) and poor condition (0-15), as shown in Table 2 . The models were categorized into three major groups consisting of species

Table 1. Fish community metrics, score criteria and class boundaries for the index of biological integrity (IBI)

\begin{tabular}{|c|c|c|c|c|}
\hline \multirow{2}{*}{ Category } & \multirow{2}{*}{ Metric component } & \multicolumn{3}{|c|}{ IBI (scores and criteria) } \\
\hline & & $1(\%)$ & $3(\%)$ & $5(\%)$ \\
\hline \multirow[t]{4}{*}{ Species composition } & (1) Total number of native species & $0-5$ & $6-11$ & $>11$ \\
\hline & (2) Number of riffle benthic species & $0-2$ & $3-4$ & $>4$ \\
\hline & (3) Number of sensitive species & $0-3$ & $4-5$ & $>5$ \\
\hline & (4) Proportion individuals as tolerant species & $>20$ & $5-20$ & $<5$ \\
\hline \multirow[t]{2}{*}{ Trophic composition } & (5) Proportion individuals as omnivores & $>45$ & $20-45$ & $<20$ \\
\hline & (6) Proportion individuals as native insectivores & $<20$ & $20-45$ & $>45$ \\
\hline \multirow[t]{2}{*}{ Fish abundance and health condition } & (7) Total Number of individual & $0-115$ & $116-228$ & $>228$ \\
\hline & (8) Proportion individuals with anomalies & $>1$ & $0-1$ & 0 \\
\hline
\end{tabular}


composition, trophic composition and fish abundance and health (Table 1).

The following metric attributes were included for species composition: total number of native fish species (1), number of riffle benthic species (2), number of sensitive species (3),

Table 2. Modified score interpretation for the index of biological integrity (IBI) values in the Pyeongchanggang River

\begin{tabular}{rcc}
\hline IBI & Score & Integrity class \\
\hline $36-40$ & A & Excellent \\
$26-35$ & B & Good \\
$16-25$ & C & Fair \\
$0-15$ & D & Poor \\
\hline
\end{tabular}

and proportion of individuals as tolerant species (4). The following were included for trophic composition: proportion of individuals as omnivore species (5) and proportion of individuals as native insectivore species (6). The following were included for fish abundance and health: total number of individuals in sample (7), and proportion of individuals with disease, tumors, fin damage and other anomalies (8).

\section{RESULTS AND DISCUSSION}

Overall, about 900 fish representing 24 species from eight families at six stations were collected in the Pyeongchanggang River (Table 3). Among these species, 16 were Korean

Table 3. Fish fauna and various guilds of tolerance, trophic condition and habitat in the Pyeongchanggang River (from April-November 2009)

\begin{tabular}{|c|c|c|c|c|c|c|c|c|c|c|c|}
\hline \multirow{2}{*}{ Species } & \multirow{2}{*}{ Tol. G } & \multirow{2}{*}{ Tro. G } & \multirow{2}{*}{ Hab. G } & \multicolumn{6}{|c|}{ Station } & \multirow{2}{*}{ Total } & \multirow{2}{*}{ RA (\%) } \\
\hline & & & & 1 & 2 & 3 & 4 & 5 & 6 & & \\
\hline \multicolumn{12}{|l|}{ Cyprinidae } \\
\hline Acheilognathus lanceolatus & IS & O & & & & & & 7 & & 7 & 0.8 \\
\hline Acheilognathus signifer ${ }^{a, b}$ & SS & 0 & & & & & & 1 & 7 & 8 & 0.9 \\
\hline Acheilognathus yamatsutae $e^{a}$ & IS & $\mathrm{O}$ & & & & & & 6 & 13 & 19 & 2.1 \\
\hline Pungtungia herzi & IS & I & & & & 5 & 2 & 82 & 24 & 113 & 12.6 \\
\hline Pseudopungtungia tenuicorpa ${ }^{\mathrm{a}, \mathrm{b}}$ & SS & I & & & 1 & 3 & 3 & 6 & & 13 & 1.4 \\
\hline Coreoleuciscus splendidus ${ }^{\mathrm{a}}$ & SS & I & RB & & & 14 & 11 & & & 25 & 2.8 \\
\hline Squalidus gracilis majimae ${ }^{a}$ & SS & I & & & & & & 1 & 3 & 4 & 0.4 \\
\hline Hemibarbus longirostris & IS & I & & & & 2 & 8 & 12 & 16 & 38 & 4.2 \\
\hline Hemibarbus mylodon ${ }^{\mathrm{a}, \mathrm{c}}$ & SS & I & & & & & & & 4 & 4 & 0.4 \\
\hline Pseudogobio esocinus & IS & I & & & & 3 & & 4 & 14 & 21 & 2.3 \\
\hline Microphysogobio yaluensis ${ }^{\mathrm{a}}$ & IS & 0 & RB & & & 2 & & 36 & 6 & 44 & 4.9 \\
\hline Microphysogobio longidorsalis ${ }^{a}$ & SS & $\mathrm{H}$ & RB & & & 5 & 3 & & & 8 & 0.9 \\
\hline Rhynchocypris oxycephalus & SS & I & & & 43 & & & 8 & & 51 & 5.7 \\
\hline Rhynchocypris kumgangensis ${ }^{a}$ & SS & I & & 28 & 25 & 3 & & & & 56 & 6.2 \\
\hline Zacco koreanus ${ }^{\mathrm{a}}$ & SS & I & & & 2 & 50 & 84 & 118 & 108 & 362 & 40.2 \\
\hline Zacco platypus & TS & 0 & & & & & 15 & 25 & 16 & 56 & 6.2 \\
\hline \multicolumn{12}{|l|}{ Balitoridae } \\
\hline Orthrias nudus & SS & I & RB & 6 & & & 2 & & & 8 & 0.9 \\
\hline Cobitidae & & & & & & & & & & & \\
\hline Koreocobitis rotundicaudata ${ }^{a}$ & SS & 0 & RB & & & & 4 & 3 & & 7 & 0.8 \\
\hline Iksookimia koreensis ${ }^{\mathrm{a}}$ & IS & I & RB & & & & 5 & & 2 & 7 & 0.8 \\
\hline \multicolumn{12}{|l|}{ Siluridae } \\
\hline Silurus asotus & TS & C & & & & & & & 1 & 1 & 0.1 \\
\hline \multicolumn{12}{|l|}{ Amblycipitidae } \\
\hline Liobagrus andersoni $i^{\mathrm{a}}$ & SS & I & RB & & & 5 & 4 & 1 & & 10 & 1.1 \\
\hline Cottidae & & & & & & & & & & & \\
\hline Cottus koreanus ${ }^{a, b}$ & SS & I & RB & & 32 & & & & & 32 & 3.6 \\
\hline \multicolumn{12}{|l|}{ Centropomidae } \\
\hline Coreoperca herzi ${ }^{a}$ & SS & C & & & & & 1 & 1 & 3 & 5 & 0.6 \\
\hline \multicolumn{12}{|l|}{ Odontobutidae } \\
\hline Odontobutis interrupta & IS & C & & & & & & & 1 & 1 & 0.1 \\
\hline No. of families & & & & 2 & 2 & 2 & 5 & 4 & 5 & 8 & \\
\hline No. of species & & & & 2 & 5 & 10 & 12 & 15 & 14 & 24 & \\
\hline No. of individuals & & & & 34 & 103 & 92 & 142 & 311 & 218 & 900 & 100 \\
\hline
\end{tabular}

Identification and classification was determined by using methods reported by Nelson (1994).

Tol. G, tolerance guild; Tro. G, trophic guild; Hab. G, habitat guild; RA, relative abundance; IS, intermediate species; O, omnivore; SS, sensitive species; $\mathrm{I}$, insectivore; RB, riffle-benthic species; $\mathrm{H}$, herbivore; TS, tolerant species; $\mathrm{C}$, carnivore. ${ }^{a}$ Endemic, ${ }^{\mathrm{b}}$ Endangered species, ${ }^{\mathrm{c} N a t u r a l}$ monument. 


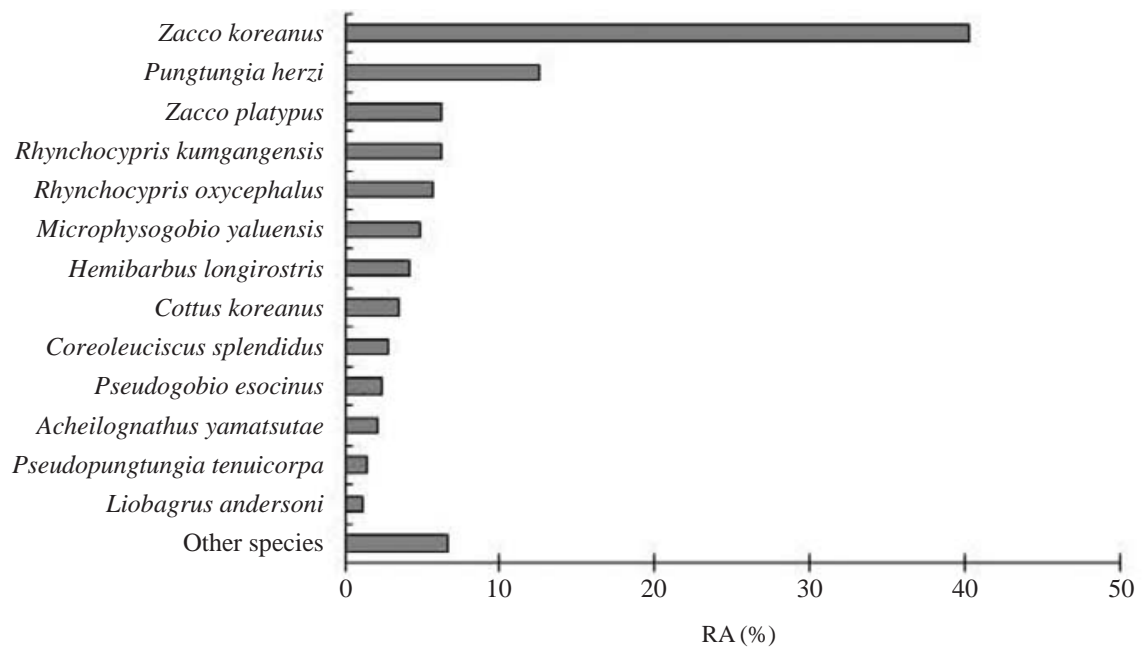

Fig. 2. Relative abundance (RA) of fish species in the Pyeongchanggang River.

endemic species (relative abundance [RA], 67.2\%), which was higher than the average of the Korean peninsula (RA 23\%) (Nam, 1996).

Cyprinidae included approximately $66.7 \%$ (16 species) of the total species collected and about $92.1 \%$ of total abundance. Subdominant families were Cobitidae (two species, RA $1.6 \%$ ).

The Korean endemic species, Zacco koreanus (362 individuals, RA 40.2\%) was the most abundant (Fig. 2). Subdominant species were native species such as Pungtungia herzi (RA $12.6 \%$ ), Zacco platypus (RA 6.2\%), Rhynchocypris kumgangensis (RA 6.2\%), and Rhynchocypris oxycephalus (RA $5.7 \%)$.

Zacco koreanus (relative abundance of endemic species [RAE] 59.8\%) was dominant among the Korean endemic species and subdominant species included Rhynchocypris kumgangensis (RAE 9.3\%), Microphysogobio yaluensis (RAE 7.3\%) and Coreoleuciscus splendidus (RAE 4.1\%).

Three endangered species were collected from the sampling area: Acheilognathus signifier (RA 0.9\%) was found at sampling stations 5 and 6, whereas Pseudopungtungia tenuicorpa (RA 1.4\%) was found at four sampling area (stations 2-5) and Cottus koreanus (RA 3.6\%) was found at three sampling sites (stations 3, 5, and 6). One natural monument species, Hemibarbus mylodon, was also sampled with an RA of $0.4 \%$ (only found at station 6).

The month with the greatest overall catch of fishes was April (258 individuals), and the lowest was November (186 individuals).

Zacco koreanus dominated during all months. Its RA in April, August, October, and November were 31.0\%, 34.8\%, $41.6 \%$, and $57.0 \%$, respectively.

Acheilognathus signifier, as an endangered species (RA
$0.9 \%$ ), was found during April and November, whereas Pseudopungtungia tenuicorpa (RA 1.4\%) was found during all months except November, and Cottus koreanus was collected in all months (RA 3.6\%). The natural monument species, Hemibarbus mylodon, was found only during the August and November at station 6 .

\section{Community index analysis}

\section{Analysis of community index at each station}

A comparison of the ecological indices at each station is shown in Fig. 3. Station 1 (two species, 34 individuals) had the lowest richness and diversity index scores (0.3 and 0.5$)$ but the highest dominance index score (0.7).

Station 2 (5 species, 103 individuals) showed a high evenness score (0.7). The highest diversity value occurred at station $6(1.8)$, whereas the lowest dominance index value was seen at station $5(0.2)$.

Rhynchocypris kumgangensis was observed in relatively high abundance and dominated station $1(82.3 \%)$ followed by Orthrias nudus as the subdominant species (17.6\%). At the second sampling station, Rhynchocypris oxycephalus (41.7\%) was dominant and Cottus koreanus (31.1\%) was the subdominant species (Table 4).

Zacco koreanus showed a high RA and was dominant at sampling stations 3-6 with proportions of 54.3\%, 59.2\%, $37.9 \%$, and $49.5 \%$, respectively. It was followed by Coreoleuciscus splendidus as the subdominant species at station 3 $(15.2 \%)$, Z. platypus $(10.6 \%)$ at station 4 and $P$. herzi at stations 5 and 6 (26.4\% and $11.0 \%$, respectively).

\section{Community index analysis for each season}

A comparison of the monthly ecological indices from AprilNovember 2009 is shown in Fig. 4. The greatest number of 


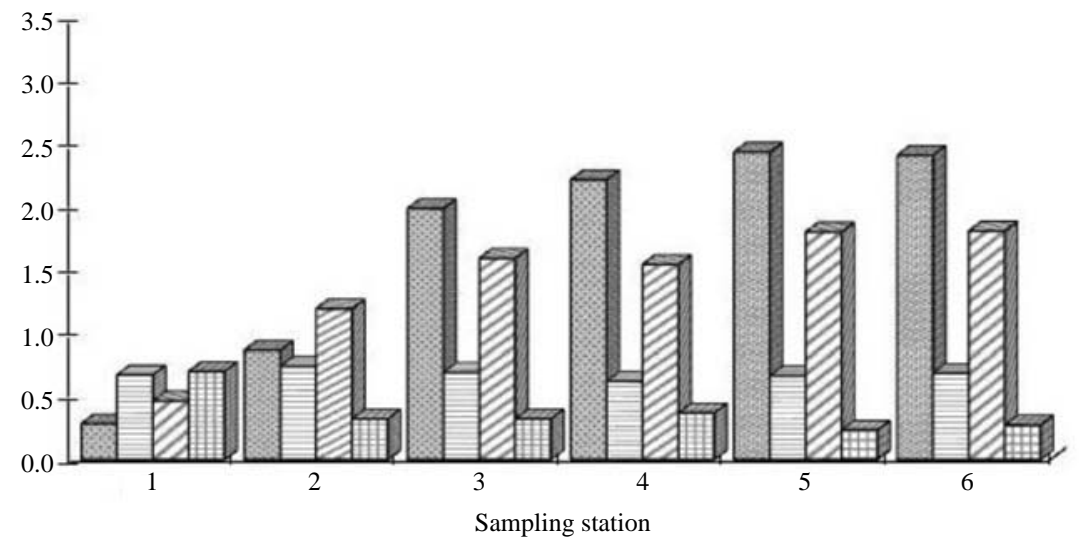

Richness $\quad \square$ Evenness $\quad$ Diversity Dominant

Fig. 3. Community analyses, based on the richness, evenness, diversity and dominance indices at each station.

Table 4. Dominant and subdominant species at each station in the Pyeongchanggang River (from April-November 2009)

\begin{tabular}{|c|c|c|c|c|}
\hline Station & Dominant & $\%$ & Subdominant & $\%$ \\
\hline 1 & $\begin{array}{l}\text { Rhynchocypris } \\
\text { kumgangensis }\end{array}$ & 82.4 & Orthrias nudus & 17.7 \\
\hline 2 & R. oxycephalus & 41.7 & Cottus koreanus & 31.1 \\
\hline 3 & Zacco koreanus & 54.3 & $\begin{array}{l}\text { Coreoleuciscus } \\
\text { splendidus }\end{array}$ & 15.2 \\
\hline 4 & Z. koreanus & 59.2 & Zacco platypus & 10.6 \\
\hline 5 & Z. koreanus & 37.9 & Pungtungia herzi & 26.4 \\
\hline 6 & Z. koreanus & 49.5 & P. herzi & 11.0 \\
\hline
\end{tabular}

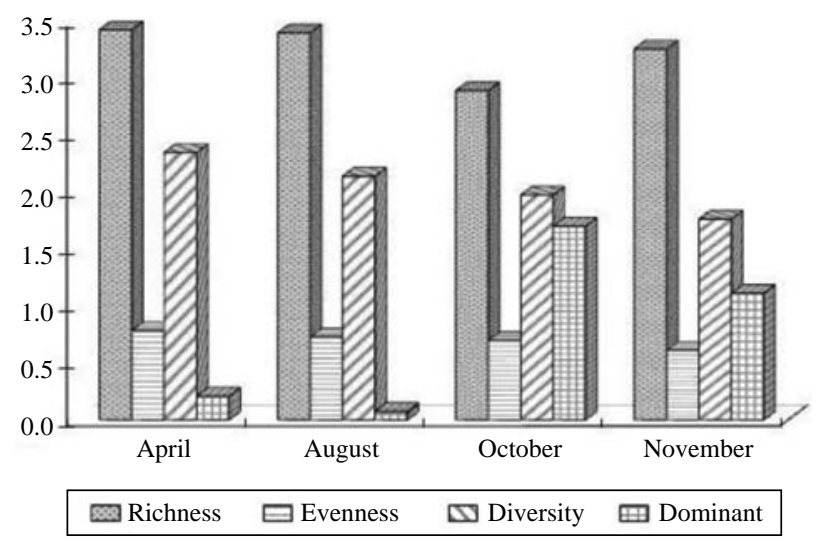

Fig. 4. Community analyses, based on the richness, evenness, diversity, and dominance indices in each month.

fish species was found in the April (20 species, 258 individuals). April also had the highest score for the richness, evenness and diversity indices.

The fewest fish were captured during the November, with the lowest evenness and diversity indices (186 individuals, 0.6 and 1.8 , respectively), whereas the lowest richness index
Table 5. Dominant and subdominant species at each month in the Pyeongchanggang River (from April-November 2009)

\begin{tabular}{|c|c|c|c|c|}
\hline Month & Dominant & $\%$ & Subdominant & $\%$ \\
\hline April & Zacco koreanus & 31.0 & $\begin{array}{c}\text { Rhynchocypris } \\
\text { oxycephalus }\end{array}$ & 15.9 \\
\hline August & Z. koreanus & 34.8 & Pungtungia herzi & 16.9 \\
\hline October & Z. koreanus & 41.6 & P. herzi & 14.9 \\
\hline November & Z. koreanus & 57.0 & $\begin{array}{l}\text { Microphysogobio } \\
\text { yaluensis }\end{array}$ & 7.0 \\
\hline
\end{tabular}

score occurred in October (2.9). October also showed the highest dominance index (1.7).

According to fish species composition, Zacco koreanus (RA 40.2\%) was confirmed to be the most dominant species in the fish community, regardless of the monthly variations in the April (31.0\%), August (34.8\%), October (41.6\%), and November $(57.0 \%)$ (Table 5).

The RA of the subdominant species P. herzi (RA 12.6\%) did not vary monthly, unlike Z. koreanus. Rhynchocypris oxycephalus was the subdominant species in the April with an RA of $15.9 \%$, but the subdominant species in August and October was Pungtungia herzi (RA 16.9\% and 14.9\%, respectively) and in November it was Microphysogobio yaluensis (RA 7.0\%) (Table 5).

\section{Analysis of ecological indicator characteristics}

According to the tolerance guild analysis, the relative proportion of tolerant species was $6.3 \%$ (57 individuals) during the survey, whereas the proportion of sensitive species was $65.9 \%$ (593 individuals) (Table 3).

The proportion of sensitive species ranged from 45 to $100 \%$ (Fig. 5). At stations 1 and 2, the proportion of sensitive species was $100 \%$ but tended to decrease at stations 3-5. At station 6 , the proportion of sensitive species was greater than 


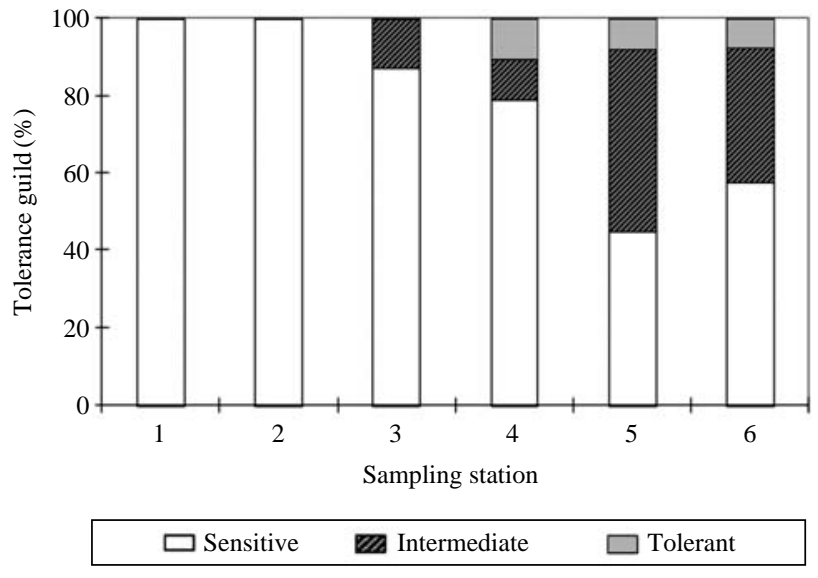

Fig. 5. Compositional changes in the tolerance guilds at each station in the Pyeongchanggang River from April-November 2009.

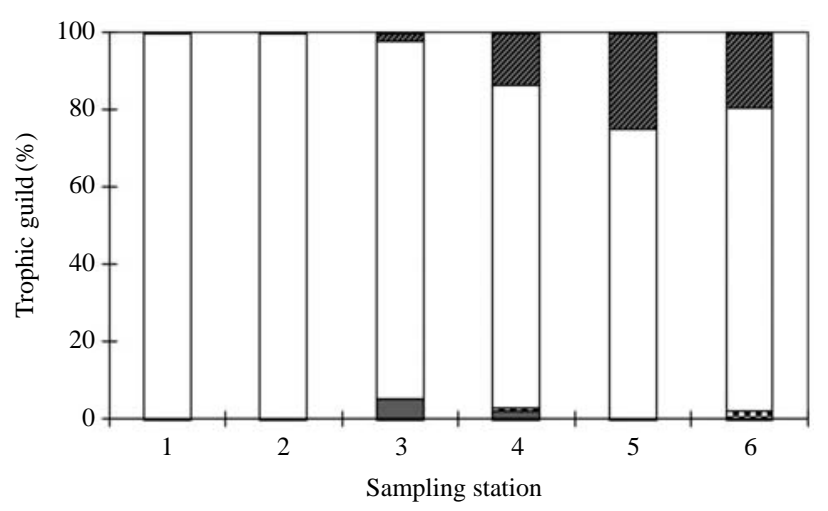

$\square$ Herbivore $\$$ Carnivore $\square$ Insectivore m Omnivore

Fig. 6. Compositional changes in the trophic guilds at each station in the Pyeongchanggang River April-November 2009.

that at station 5. The proportion of tolerant species ranged from 8 to $11 \%$ and was only found at stations $4-6$, whereas intermediate species were found at stations $3(13 \%), 4(11 \%)$, $5(47 \%)$, and $6(35 \%)$.

The trophic guilds analysis revealed that insectivores dominated all sampling stations (Fig. 6). The proportion of insectivores was $100 \%$ at stations 1 and 2 , then tended to decrease at stations 3-5, ranging from 75 to $92 \%$. At station 6, the proportion of insectivores was greater than that at station 5 . Herbivores, such as Microphysogobio longidorsalis were found at stations 3 and 4 with proportions of $5 \%$ and $2 \%$, respectively.

Carnivores were found at stations 4-6 with proportions ranging from 0.3 to $2 \%$. The proportion of omnivores increased downstream, from $2 \%$ at station 3 to $25 \%$ at station 5 . At station 6 , the proportion of insectivores decreased to $19 \%$ (Fig. 6).

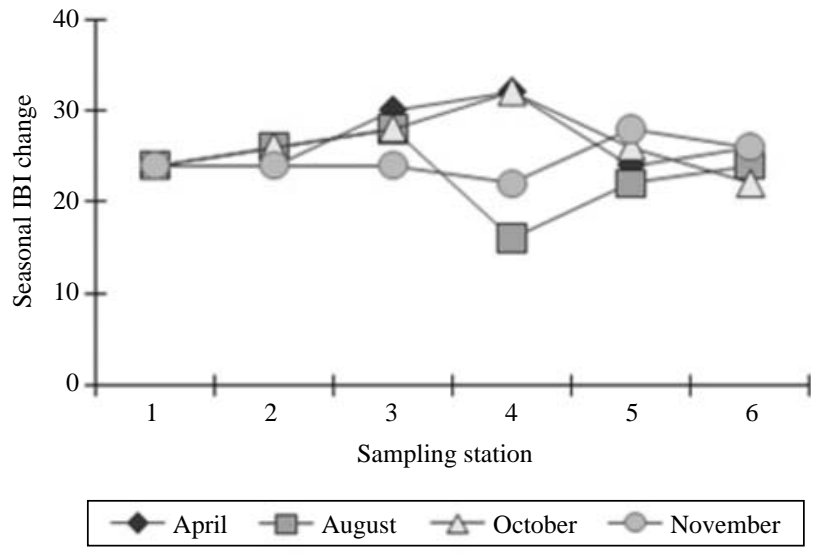

Fig. 7. Monthly changes in the index of biological integrity (IBI) at each station in the Pyeongchanggang River from April-November 2009.

\section{IBI}

The ecological stream health assessment, based on the IBI, indicated that health varied with location and month (Fig. 7).

IBI values ranged from 24 to 32 during April and averaged $27(n=6)$, indicating a "good condition." The condition varied in other seasons: a "fair condition" for August (IBI average 23) and November (IBI average 25) and a "good condition" during the October (IBI average 26). The total IBI value for all months and stations during 2009 averaged $25(n=24)$ and was considered "fair condition."

\section{Comparison to previous studies}

Several fish community studies has been conducted on the Pyeongchanggang River. A fish species distribution in Gangwon-do was conducted by Choi (1986), followed by a biological habitat assessment by An et al. (2001). The most recent study concerned the fish community and inhabitation of legally protected species by Lee et al. (2006).

Choi (1986) reported about 35 fish species from nine families, followed by An et al. (2001) who found approximately 28 species from seven families. Lee et al. (2006) reported that approximately 35 species from 10 families were found in the Pyeongchanggang River.

The species investigated during 1986-2009 varied. Nineteen species from the current research $(75 \%)$ were found in previous studies, including: Acheilognathus yamatsutae, Pungtungia herzi, Coreoleuciscus splendidus, Hemibarbus longirostris, Pseudogobia esocinus, Microphysogobio longidorsalis, Rhynchocypris oxycephalus, R. kumgangensis, Zacco koreanus, Zacco platypus, Orthrias nudus, Iksookimia koreensis, Koreocobitis rotundicaudata, Silurus asotus, Liobagrus andersoni, and Coreoperca herzi. The natural monument, H. mylodon and two endangered fish species (Achei- 
lognathus signifier and Pseudopungtungia tenuicorpa) were also reported in all studies.

Species that were present in 2006 but did not occur in the present survey were: Lampetra reissneri, Anguilla japonica, Acheilognathus rhombeus, Gobiobotia macrocephala, $R$. steindachneris, Odontobutis platycephala (recorded only in 2006); Carassius auratus, Sarcocheilichthys variegates wakiyae, G. brevibarba, S. microdorsalis, Pseudobagrus koreanus, Siniperca scherzeri (recorded in 1986, 2001 and 2006), and Hemibarbus labeo (recorded in 2001 and 2006).

Another endangered species, Cottus koreanus, was reported in the Pyeongchanggang River in 1986 and the current study but not in 2001, 2006.

Sixteen Korean endemic species (RA 67.2\%) were collected during the study. The proportion of endemic Korean species was higher than the average RA $(23 \%)$ of the entire endemic species of Korea (Nam, 1996), indicating that the proportion of endemic Korean species found in this study was higher than the normal proportion throughout the Korean peninsula. Exotic fish, which are introduced to a country outside of their natural range (Shafland and Lewis, 1984) were not found.

Zacco koreanus was only found and dominated at the fourth order river (stations 3-6), whereas the third order river was dominated by R. kumgangensis (station 1) or R. oxycephalus (station 2).

Twenty four species emerged in this study. It was similar to the 2001's survey and it was less than 2006's survey. I think by the survey area, timing and tool is shown in the difference.

Species diversity was relatively low at station 1 , whereas stations 2-6 showed a medium level of diversity. Overall, fish species richness in the Pyeongchanggang River was low, but the evenness score could be classified as high $\left(\mathrm{J}^{\prime}>0.6\right)$.

The species evenness, richness and diversity indices decreased monthly from April to November. The evenness index varied from 0.6 to 0.8 and could be classified as high, whereas the richness index decreased from 3.4 to 3.3 and could be classified as low $(\mathrm{R}<3.5)$. The species diversity index also showed a similar pattern with previous indices and scores decreased from April to November in the range from 2.3 to 1.8 , which could be considered a medium level of diversity.

The ecological stream health assessment, based on the IBI, indicated that stream health varied depending on the location and sampling time. IBI values at each site and month ranged from 16 to 34 with an average of $25(n=24)$, indicating a "fair condition."

The results of this study suggest that the Pyeongchanggang River is one of the most important environmental resources for fish diversity and conservation, particularly for the ende- mic and endangered species of Korea.

\section{ACKNOWLEDGEMENTS}

This study was performed with the financial support of Sangji University, 2009.

\section{REFERENCES}

Allan JD, Castillo MM, 2007. Stream ecology: structure and function of running waters. 2nd ed. Springer, Dordrecht, pp. 1-436.

An KG, Jung SH, Choi SS, 2001. An evaluation of water environment, Pyeongchang River using the index of biological integrity and qualitative habitat evaluation index. The Korean Society of Limnology, 34:153-165.

Choi KC, 1986. The nature of Gangwon province (freshwater habitat). Gangwon Provincial Board of Education, Chuncheon.

Federal Interagency Stream Restoration Working Group, 1998. Stream corridor restoration: principle, processes and practices. By the Federal Interagency Stream Restoration Working Group (FISRWG) [Internet]. United States Department of Agriculture, Washington, DC, Accessed 2 Sep 2010, <http://www/usda.gov/stream_restoration>.

Friedlander AM, Parrish JD, 1998. Temporal dynamics of fish communities on an exposed shoreline in Hawaii. Environmental Biology of Fishes, 53:1-18.

Hugueny B, Camara S, Samoura B, Magassouba M, 1996. Applying an index of biotic integrity based on fish assemblages in a west African river. Hydrobiologia, 331:71-78.

Karr JR, 1981. Assessment of biotic integrity using fish communities. Fisheries, 6:21-27.

Kim IS, Choi Y, Lee CL, Lee YJ, Kim BJ, Kim JH, 2005. Illustrated book of Korean fishes. Kyo-Hak Publishing Co., Ltd., Seoul, pp. 1-615 (in Korean).

Kim IS, Park JY, 2002. Freshwater fishes of Korea. Kyo-Hak Publishing Co., Ltd., Seoul, pp. 1-465.

Lee KY, Jang YS, Choi JS, 2006. Fish fauna and inhabitation of legally protected species in the Pyeongchang River. Korean Journal of Environment and Ecology, 20:331-339.

Margalef R, 1958. Information theory in Ecology. General Systems, 3:36-71.

Nam MM, 1996. Present status of Korean freshwater fish. '96 Symposuim of the Korean Society of Limnology, Korean Society of Limnology, Seoul, pp. 31-45.

Nelson JS, 1994. Fishes of the world. 3rd ed. John Wiely \& Sons, New York, pp. 1-624.

Ohio Environmental Protection Agency, 1989. Biological criteria for the protection of aquatic life. Vol. III, Standardized biological field sampling and laboratory method for assessing fish and macroinvertebrate communities. Ohio Environmental Protection Agency, Columbus, OH, pp. 1-42. 
Pielou EC, 1966. The measurement of diversity in different types of biological collections. Journal of Theoretical Biology, 13:131-144.

Rankin ET, Yoder CO, 1999. Method for deriving maximum species richness lines and other threshold relationships in biological field data. In: Assessing the sustainability and biological integrity of water resources using fish communities (Ed., Simon TP). CRC Press, Washington, DC, pp. 611-624.

Sanders RE, Miltner RJ, Yoder CO, Rankin ET, 1999. The use of external deformities, erosions, lesions and tumors (DELT anomalies) in fish assemblages for characterizing aquatic resources: a case study of seven Ohio streams. In: Assessing the sustainability and biological integrity of water resources using fish communities (Ed., Simon TP). CRC Press, Washington, DC, pp. 225-248.

Shafland PL, Lewis WM, 1984. Terminology associated with introduced organisms. Fisheries, 9:17-18.

Shannon CE, Weaver W, 1949. The mathematical theory of communication. University of Illinoi Press, Urbana, IL, pp. 1-117.

Simpson EH, 1949. Measurement of diversity. Nature, 163:688.

Received March 17, 2011 Accepted June 16, 2011 